D.E.L.T.A., Vol. 15, N. ${ }^{\circ}$ EsPECIAL, 1999 (201-232)

\title{
Retrospectiva Sociolingüística: Contribuições do Peul
}

(Sociolinguistic Overview: PEUL's Contribution)

\begin{abstract}
Maria da Conceição de PaIva (Universidade Federal do Rio de Janeiro) Maria Marta Pereira SCHERRE (Universidade Federal do Rio de Janeiro/

Universidade de Brasília)
\end{abstract}

ABSTRACT: In this article we focus PEUL's (Programa de Estudos sobre o Uso da Lingua) contribution to Brazilian Sociolinguistics, and, specifically, to variationist studies. We start by providing an overview of Rio de Janeiro variable phenomena. Then we show the spread of variation domain and emphasize the systematicity and regularity of a linguistic variable - the formal parallelism - on phenomena of language variation and change, and show some patterns of correlation between language and social structure.

KEY WORDS: Systematic Variation; Levels of Variation; Linguistic Change; Usage Universals.

Palavras-chave: Variação Sistemática; Níveis de Variação; Mudança Lingüística; Universais de Uso.

0. Introdução

Nesta oportunidade, em que se comemoram os 30 anos de criação da Associação Brasileira da Lingüística (ABRALIN), coube-nos a tarefa de precisar as contribuições do grupo de pesquisa Programa de estudo sobre o uso da língua (PEUL) para o desenvolvimento da Sociolingüística no Brasil ${ }^{1}$. Não podemos deixar de ressaltar a inquestionável importância dessa associação, cuja história se confunde com a própria história da Lingüística no Brasil. A consolidação dos estudos lingüísticos brasileiros em muito pôde se beneficiar da existência de uma entidade que, reunindo pesquisadores das mais diferentes correntes teóricas, vem contribuindo de forma significativa para o conhecimento da nossa realidade lingüística. A emergente Sociolingüística brasileira dos anos 60 pôde encontrar na ABRALIN um fórum de debates aberto e, ao mesmo tempo, agregador, que possibilitou o amadurecimento e a expansão de uma subárea com delimitação epistemológica própria, que toma a

\footnotetext{
1 Agradecemos a Paula Pereira Scherre pela ajuda na montagem das referências bibliográficas e pela leitura criteriosa da versão final deste texto. Inconsistências formais que restarem são de nossa inteira responsabilidade.
} 
heterogeneidade lingüística ordenada como um objeto passível de análise científica.

A Sociolingüística despontou, no contexto dos estudos lingüísticos brasileiros, como uma área fértil e desafiadora, dada a necessidade de compreender a realidade lingüistica de um país em que diferentes dimensões sociais se conjugam para a configuração de um quadro sociolingüístico complexo: uma realidade que até um passado bem recente era conhecida apenas de forma pontual ou, por que não dizer, muitas vezes impressionística. No curto espaço de tempo em que a Lingüística se academicizou no Brasil, ressaltam questões ligadas aos estereótipos homogeneizantes nacionais, às especificidades do português brasileiro em relação à mãe européia, à diversidade e ao contato entre línguas no espaço geográfico brasileiro, à contribuição dos elementos indígenas e africanos na configuração da nossa variabilidade, aos reflexos de uma marcada estratificação social na heterogeneidade dialetal. Germinando em trabalhos pioneiros como os de Amadeu Amaral (1920), Clóvis Monteiro (1933), Mário Marroquim (1945), Antenor Nascentes (1953), entre diversos outros, a análise da realidade lingüística brasileira tem sido, no decorrer dos últimos anos, objeto do esforço continuado de muitos pesquisadores e diversos grupos de pesquisa localizados nos mais diferentes pontos deste país. Destaquemos aqui o trabalho dos modernos dialetólogos brasileiros, traduzido nos múltiplos atlas lingüísticos, que contribuíram para a precisão das realidades lingüísticas regionais (Ferreira et alii, 1994; Aguilera, 1998) e a importância do Projeto NURC - Norma urbana culta - (Cunha, 1989). Os diversos grupos de pesquisa variacionista e não variacionista que despontaram e cresceram nos últimos anos enriqueceram inegavelmente nossa compreensão acerca dos condicionamentos lingüísticos e sociais da modalidade culta e não culta do português do Brasil. Incorrendo no risco da enumeração, ${ }^{2}$ devemos lembrar aqui o projeto Competências básicas do português (Lemle \& Naro, 1977), o VARSUL - Variação lingüística urbana da Região Sul -(Fernandes, 1996:89), o VALPB - Variação lingüística no Estado da Paraíba - (Hora, 1998), o LUAL - A língua usada em Alagoas (Moura, 1997); Dialetos sociais cearenses (Aragão \& Soares, 1996), o projeto de estudo da confluência dialetal na nova capital brasileira (Bortoni, 1984), o grupo de estudos Discurso e Gramática (Martelotta et alii, 1996) e a recente empreitada da Gramática do português falado (Castilho, 1990), todos mais voltados para a linguagem dos grandes centros urbanos. Destacam-se também

\footnotetext{
${ }^{2}$ Inúmeras são as pesquisas individuais desenvolvidas sob a ótica da Teoria da Variação. Fazer referência a todas elas neste espaço seria impossível.
} 
pesquisas que focalizam dialetos rurais (Rodrigues, 1974; Jeroslow, 1974; Nina, 1980; Veado, 1982), ou comunidades específicas, como as pesqueiras do Estado do Rio de Janeiro, projeto APERJ - Altas etnolingüístico dos pescadores do Estado do Rio de Janeiro (Brandão \& Vieira, 1998), ou comunidades isoladas brancas (Isensee, 1964; Callou, 1998) e comunidades isoladas negras (Ferreira, 1994; Careno, 1992; Vogt \& Fry, 1997). Ampliando os estudos de comunidades isoladas negras e de áreas específicas do interior baiano, assume corpo o projeto Vestígios de dialetos crioulos em comunidades afro-brasileiras (Baxter \& Lucchesi, 1997) e emerge o projeto A língua portuguesa no semi-árido baiano (Almeida \& Carneiro, 1998). Perscrutando aspectos estruturais e sociais na linha do tempo, destaca-se o Programa para a história da língua portuguesa (PROHPOR) (Mattos e Silva, 1996) e cria-se o Projeto para a história do português brasileiro (Castilho, 1998). Não podemos deixar de lembrar também as conquistas substanciais do grupo coordenado pelo saudoso Fernando Tarallo, com a sua proposição de uma Sociolingüística Paramétrica, levada à frente por um número significativo de pesquisadores, que com muito contribuiu para o conhecimento das características do português brasileiro e das mudanças em curso nessa variedade (cf., por exemplo, Tarallo, 1983; 1989; Roberts \& Kato, 1993; Cerqueira, 1990; Pagotto, 1992; Nunes, 1995; Duarte, 1995; 1998; Ramos 1997;1998/2000; Cyrino, 1997; Corrêa, 1998). Com suas naturais especificidades teórico-metodológicas, a convergência de objetivos mais amplos de todas as pesquisas relacionadas tem possibilitado acúmulo considerável de conhecimento acerca da multidialetação diatópica e diastrática, da sistematicidade do uso lingüístico e dos processos de mudança na variedade brasileira do português.

O nosso objetivo neste artigo consiste apenas em ressaltar alguns aspectos teóricos e metodológicos que se consolidaram ou emergiram nos múltiplos trabalhos realizados pela equipe de pesquisadores do PEUL. Esse grupo de pesquisa vem se caracterizando, ao longo dos seus quase vinte anos de existência, pelo interesse no estudo da variedade não culta do português falado no Rio de Janeiro e pela busca de uma teoria mais geral da heterogeneidade e da mudança lingüísticas. A própria sigla PEUL já traz embutido o objetivo central dos pesquisadores que integram ou integraram o grupo: a legitimação de estudos sobre o uso lingüístico, nas suas diferentes modalidades. Esse objetivo que, no primeiro momento, se direcionou para a

\footnotetext{
${ }^{3}$ Atualmente, o grupo PEUL é composto pelos seguintes pesquisadores: Anthony Julius Naro, Christina Abreu Gomes, Cláudia Roncarati de Souza, Helena Gryner, Maria Cecília Mollica, Maria da Conceição de Paiva, Maria Eugênia Lamoglia Duarte, Maria Luiza Braga, Maria Marta Pereira Scherre, Nelize Pires de Omena e Vera Lúcia P. Pereira da Silva.
} 
língua falada não-culta do Rio de Janeiro, constituiu o vetor básico de uma trajetória centrada na análise de parâmetros internos e externos de explicação da variação e da mudança lingüísticas e de instrumentos metodológicos que garantam o rigor da análise de dados. Mesmo incorrendo no risco de não refletir com fidelidade o valor intrínseco de cada trabalho, não pretendemos fazer aqui uma retrospectiva resumitiva de todas as pesquisas realizadas pelos integrantes do grupo ${ }^{3}$. Enfatizaremos, sobretudo, alguns resultados que permitiram depreender, a partir de análises empíricas particulares, a regularidade de alguns princípios sobre a variação e a mudança lingüísticas e desvendar alguns aspectos da interface língua/sociedade. Antes de nos deter nesses dois pontos, traçamos um breve esboço do universo de variação analisado pelo grupo, com o objetivo de deixar clara uma trajetória que culminou na convergência de diferentes paradigmas interpretativos da variação e de mudança lingüísticas.

\section{Um panorama do universo variável do Rio de Janeiro}

Concebido no final da década de setenta, por um grupo de pesquisadores reunidos em torno de Anthony Julius Naro, o PEUL se consolidou, durante os anos oitenta (Braga et alii, 1991; Silva \& Votre, 1991; Tarallo, 1991; Silva \& Scherre, 1996), como um foco irradiador da Sociolingüística Quantitativa nos moldes do paradigma laboviano (Weinreich, Labov \& Herzog, 1968; Labov, 1975; Sankoff, 1988a; 1988b). Na sua gênese, alguns princípios estavam necessariamente envolvidos: (1) a dissociação entre estrutura lingüística e homogeneidade - a língua é tomada como uma estrutura inerentemente variável e a variação livre como passível de descrição sistemática, em função de restrições lingüísticas e não-lingüísticas; (2) a rejeição da intuição como fonte dos dados lingüísticos, analisando-se, portanto, a língua inserida no contexto social e buscando dar conta da estrutura gramatical no discurso, a partir da conversação natural, de narrativas formais, de gêneros escritos diversos etc.; (3) a pressuposição de que um modelo de língua que acomoda os fatos variáveis e suas restrições lingüísticas e não-lingüísticas conduz a descrições e explicações mais adequadas e resolve questões ligadas à mudança lingüística; (4) a aceitação de motivações internas e/ou externas em competição, assumindo que a explicação dos fatos lingüísticos pode estar fora do sistema lingüístico; (5) a atribuição de importância à freqüência dos dados, conduzindo necessariamente à sua quantificação em função de restrições que operacionalizam hipóteses passíveis de serem refutadas; (6) a pressuposição de que os fatores das possíveis restrições têm um efeito fixo, podendo, conseqüentemente, ser isolados, medidos, generalizados e explicados em 
função de princípios internos e externos à língua.

Formulado com o objetivo precípuo de estudar fenômenos variáveis presentes no português falado por cariocas não-cultos, através de uma metodologia quantitativa, o primeiro projeto se colocou a tarefa de constituir uma amostra estratificada da variedade em foco. Inspirando-se no modelo do corpus constituído para o francês de Montreal (Thibault \& Vincent, 1990), o grupo coletou, transcreveu e armazenou eletronicamente 64 horas de gravação com falantes cariocas estratificados segundo variáveis sociolingüísticas clássicas (sexo, idade e escolaridade) e distribuídos por diferentes bairros da cidade.

Essa amostra, mais conhecida por Corpus Censo, ${ }^{4}$ revelou-se fértil manancial para o estudo da heterogeneidade da fala carioca. Foi possível contatar que, a depender da conjugação de fatores lingüísticos e extralingüísticos, os carioca, em dias de sol, curte ir na praia e, depois, adora toma umas cervejinha, assistino o jogo de futebol. A frase anterior ilustra algumas variações já estudadas a partir do Corpus Censo, mas, certamente, não as esgota. Estudos de diversos fenômenos variáveis em todos os subsistemas lingüísticos permitiram a construção de um quadro bastante completo do universo da variação presente na fala dos cariocas com escolarização média.

No nível fonético-fonológico, destacam-se, entre os aspectos já examinados pelo PEUL, a tendência à monotongação dos ditongos decrescentes [ey] e [ow] (peixe/pexe, couro/coro) (Paiva, 1996a); a estigmatização da alternância entre as líquidas ou a queda de [r] nos grupos consonantais (blusalbrusa, flamengolframengo próprio/própio, problemalpobrema) (Mollica \& Paiva, 1991;1993); a estabilidade da supressão de /d/ na seqüência -ndo (andando/andano, bebendo/ bebeno) e a significativa restrição do processo ao sufixo de gerúndio (Mattos \& Mollica, 1989); o reforço da palatalização, competindo com as variantes alveolar, aspirada e zero nas diversas realizações do $\{\mathrm{S}\}$ pósvocálico [meyZum/meyzmu/meúmu/memo] (Scherre \& Macedo, 1989; 1996); a redução variável da preposição para (para, pra e pa) (Felgueiras, 1993); a implementação da queda de [r] pós-vocálico, em especial nos infinitivos (beber/bebê, cantar/canta) (Lima, 1992); a prótese (voarl

${ }^{4} \mathrm{O}$ Corpus Censo é constituído por 48 horas de gravação com falantes adultos, divididos por três faixas etárias (15-25 anos, 26-49 anos e mais de 50 anos) e uma amostra de crianças na faixa de 7 a 14 anos (Silva, 1996a). 
avoar) e aférese (assistir/sistir) de segmentos fônicos (Gonçalves, 1993).

No nível morfossintático, um conjunto significativo de fenômenos foi abarcado. Os estudos sobre a concordância de número trouxeram à luz o comportamento simétrico dos três processos variáveis de concordância: a variação de concordância no sintagma nominal (os meninos/os menino; as portas abertas/as porta aberta) (Scherre, 1988; 1989; 1994; 1996a; 1997; 1998; Scherre \& Naro, 1997), entre verbo e sujeito (Eles ganham dimais/Eles ganha dimais) (Scherre \& Naro, 1993; 1997; Naro \& Scherre, 1996a) e dos predicativos e particípios passivos com o sujeito (as coisas tão caras/as coisa tá cara; os meus filhos foram amamentados/os meus filhos foram alfabetizado) (Scherre, 1991; Scherre \& Naro, 1997).

Análises do uso variável de preposições revelaram aspectos importantes quanto aos processos de regência verbal. A análise da regência do verbo ir (ir ao Maracanã/Eu ia pró sítio do meu tio/Meu pai que ia no açougue) reforçou a hierarquização entre as três variantes: a preposição a é mais padrão do que para, seguindo-se, então, a preposição em (Mollica, 1996a) e evidenciou a importância de fatores de natureza semântica. A instabilidade do sistema preposicional fica evidente ainda na tendência à inserção da preposição de em contextos em que não se prevê sua ocorrência - dequeísmo - (Basta dizer isto: de que esta metáfora das luzes é exclusiva do século XVIII) ou de sua queda em contextos onde é esperada - queísmo - (ela não gosta que interrompam a aula para pedir explicações) (Mollica, 1989a; 1991a; 1991b; 1995a). Um estudo mais abrangente de processos variáveis de regência verbal focalizou a alternância a/para ou o apagamento do nexo preposicional em contextos de verbos bi-transitivos (Eu sabia que você ia pedir o dinheiro $a$ ele0/O cara vem do Brasil, um nordestino pra dar um presente pro papa/Num tem um senhor lá na Itália querendo dar um presente 0 papa), a alternância entre a/para com verbos transitivos indiretos (Seu Lacava mesmo pertence aos vicentinos/Nós estamos precisando de uma pessoa lá pra ficar na parte que pertence $0 \mathrm{o}$ escritório) e, ainda, a presença ou ausência das preposições em (Vamos pensar em viver ainda mais/Penso 0 fazer um negócio, penso 0 sair) e de (Então o ser humano precisa 0 um espaço pelo menos que ele pode abrir os braços.../Eu acho que o ser humano, ele, na sua essência, ele precisa- precisa de espaço à sua volta) (Gomes, 1996).

As análises de variações entre formas pronominais desvendaram muitos dos movimentos no interior desse subsistema no português brasileiro. O estudo da alternância entre as formas seu/dele (Comprei seu livro/Comprei o livro 
dele) mostra o estágio avançado de um processo de mudança que atinge o sistema de referência possessiva na 3르 pessoa do singular (Silva, 1991; 1996b). A análise da alternância entre nós e a gente fornece fortes evidências de uma mudança das formas de referência à primeira pessoa do plural, com gradativa substituição de nós pela expressão genérica a gente, em diversas funções sintáticas (que nós temos aqui uma dificuldade muito grande de colocar a documentação do bar em dia/Então, a gente num tem condição de fazer uma documentação certa) (Omena, 1987; 1996).

O emprego supostamente facultativo de artigos frente a possessivos e patronímicos ( $o$ meu livro/meu livro, $o$ Arthur/Arthur) foi submetido ao rigor da metodologia quantitativa, desnudando-se, assim, diferenças significativas de contextos favoráveis a uma ou outra variante (Silva, 1996c).

Mereceram também atenção especial a definição de variáveis lingüísticas motivadoras do uso do pronome indefinido substantivo tudo em variação com o pronome indefinido adjetivo todo(a)(s) (escola para todos os ofícios/ cria peixe aí, em tudo o quintal; esses troço tudo eu pego para ler/porque eles cortaram o cabelo dela todo (Pinto, 1996) e a alternância entre os verbos impessoais ter, haver, existir (Tem muitos livros na mesa/Há muitos livros na mesa/Existem muitos livros na mesa) (Fioretti, 1996). ${ }^{5}$

2. Alargando os domínios da variação

Desde os seus primeiros passos, o PEUL foi ampliando seus interesses, através da: (a) incorporação de outras amostras do português falado, assim como de amostras de língua escrita antiga e contemporânea; (b) incorporação nos estudos variacionistas de fatores ligados à organização do discurso, ao processamento da fala e ao processo interacional; (c) análise de fenômenos variáveis situados fora do domínio da sentença; (d) estudo de aquisição e mudança de processos variáveis no português falado como primeira língua (L1) e como segunda língua (L2).

O estudo dos padrões de variação na modalidade escrita, comparativamente aos da fala, tem se revestido de particular interesse, pois, do ponto de vista teórico, fornece subsídios para questões ligadas à

\footnotetext{
${ }^{5}$ Uma parte dos trabalhos aqui citados foram reunidos sob o título de "Padrões sociolingüísticos: análise de fenômenos variáveis do português falado no Rio de Janeiro", organizado por Silva \& Scherre (1996).
} 
implementação das mudanças e, do ponto de vista prático, permite incursionar com mais propriedade nas questões relativas ao ensino de aspectos do português não adquiridos como primeira língua. As alternativas de realização do sujeito de 1 ${ }^{\text {a. }}$, 2a . e 3․ pessoas (Acho que ele também tinha uma quedinha por mim, mas 0 não ousava sequer sair do sério. Ele é um cara muito legal não é?) foram analisadas na escrita informal, representada por cartas pessoais (Paredes da Silva, 1988; 1993; 1996). O estudo permite depreender pontos de interseção entre as modalidades falada e escrita e especificidades dessa última no que tange à realização do parâmetro sujeito nulo.

O estudo da concordância verbal de número na escrita padrão contemporânea tem propiciado uma análise mais generalizante de restrições lingüísticas relevantes para a variação na fala e na escrita. Os traços da saliência - fônica, de posição e de animacidade, estabelecem um jogo interessante com o traço sintático de número tanto no sentido de reter o controle da concordância no núcleo do sujeito quanto no sentido de permitir o deslocamento deste controle para o núcleo nominal do sintagma preposicional mais à esquerda (Scherre \& Naro, 1998a; 1998b; Naro \& Scherre, 1998). A estrutura das frases imperativas também é abordada na confluência entre fala e escrita, revelandose, nos dados até então analisados, certa complementaridade no uso da forma indicativa, mais freqüente na fala, e da forma subjuntiva, mais freqüente na escrita. Restrições de natureza lingüística - semântica, sintática e fonológica e não-lingüística - tipo e formalidade do evento, faixa etária e anos escolarização - entram em jogo no entendimento deste fenômeno (Scherre et alii, 1998).

O interesse pela língua escrita de séculos passados é um corolário natural da conjugação, implicada no próprio paradigma sociolingüístico, entre sincronia e diacronia. A necessidade de buscar no tempo real comprovação para as evidências do tempo aparente, com o objetivo de identificar no sistema as raízes da variação e de entender os caminhos da mudança, tem motivado o exame de textos antigos. Apenas para citar alguns exemplos de análise sistemática do tempo real, no estudo do artigo definido diante de possessivos e de patronímicos são examinados dados do século XV ao século XX (Silva, 1996c); a origem do (de)queísmo é minuciosamente investigada em diversos corpora diacrônicos, do século XII ao século XX (Mollica, 1989a; 1995a) e, no estudo da concordância verbal, percorre-se o período compreendido entre os séculos XIII a XV (Naro \& Scherre, 1998; no prelo; Scherre \& Naro, 1998a; 1998b). O percurso das formas sintáticas de indeterminação do sujeito está sendo rastreado a partir do século XIV até o século XX, procurando-se identificar novas estruturas implementadas na língua (Omena, em 
desenvolvimento). De forma semelhante, a gênese das estruturas de negação é investigada em textos do português arcaico (Roncarati, 1997).

As análises de textos antigos têm fornecido argumentos para as discussões seculares sobre a natureza e origem do português do Brasil, que opõem adeptos de abordagens tão distintas como a hipótese da descrioulização ortodoxa (Jeroslow, 1975; Guy, 1989) à da mudança natural (Naro, 1981; Tarallo, 1993), passando por hipóteses intermediárias associadas à mudança natural acelerada por condições sociais particulares (Câmara Jr., 1975; Silva Neto, 1986) ou à transmissão lingüística irregular (Holm, 1992; Baxter \& Lucchesi, 1997), ambas pressupondo uma fase lingüística crioula, ou à mudança natural acelerada por condições sociais diversas, sem pressuposto de fase lingüística crioula (Naro \& Scherre, 1993a; no prelo).

A incorporação de fatores de natureza discursivo/pragmática se impõe pela necessidade de explicar fenômenos, que, situados no nível oracional, exigem a consideração de contextos mais amplos que permitam controlar as funções das estruturas lingüísticas. O estudo de fenômenos de topicalização e deslocamento de constituintes sintáticos (Pós-operatório todo muito tem) (Braga, 1986); da ocorrência de traços suprassegmentais em fronteiras sintáticas (A minha paixão pelo futebol (pausa) é desde criança/ Bem poucas pessoas (ruptura entonacional) tinha rádio/Eu não podia ver uma bola, (Mollica, 1993; 1996b, Braga \& Mollica, 1986); da inversão do sujeito (Cem mil cruzeiros faturou a nossa barraca) (Votre \& Naro, 1989); da dupla realização do sujeito (Aí o filho dele e mais uns amigos dele, só eles ali, eles conseguem formar um império desgraçado contra o ... do Dart..) (Braga, 1987); dos diversos tipos de construções de foco (Foi isso que aconteceu, A minha tia é que cozinha, Quem segura é o Sandro, Eles ficam é com ciúme, Ele que organiza os desfiles aqui) (Braga, 1991); da realização dos sujeitos de 1 $1^{\mathrm{a}}, 2^{\mathrm{a}}$ e $3^{\mathrm{a}}$ pessoas (Paredes da Silva, 1988; 1994); e da variação nas estruturas de negação (Não sei/Não sei não/Sei não) demonstra que fatores como contraste, coesão textual, continuidade referencial e status informacional dos referentes, por exemplo, exercem incontestável pressão em processos de variação sintática (Roncarati, 1994; 1996).

Preocupados com a dimensão funcional da variação, diversos trabalhos ressaltam também a relevância de fatores de processamento da fala, como dimensão dos constituintes, traduzível no princípio da quantidade, distância e presença de material interveniente para fenômenos de níveis fonético/ fonológico (Mollica, 1989b) e sintático (Braga, 1986; 1987; 1991). 
A incorporação de aspectos discursivos e de processamento na análise variacionista, que alinha o grupo a paradigmas funcionalistas de estudo da linguagem, constitui uma tentativa de transpor o plano descritivo da variação, buscando a razão de ser da coexistência de duas ou mais formas de dizer a mesma coisa. Esse avanço se torna possível porque o grupo trabalha com uma noção estrita de significado, requerendo, na caracterização das variantes, apenas a equivalência de significado referencial. Outros tipos de significado, e mesmo nuances de significado referencial, são tomados como variáveis independentes (Callou, Omena \& Silva, 1991; Paredes da Silva, 1992; Mollica, 1994b). O enquadre discursivo/funcional do grupo poderia ser resumido, retomando uma expressão já utilizada por Naro \& Votre (1992), como "uma análise lingüística no discurso", ou seja, uma análise das pressões de condicionamentos do co-texto e do contexto sobre a estrutura lingüística.

A abordagem discursivo/funcional suscitou saudável discussão entre funcionalistas (Votre \& Naro, 1989; Naro \& Votre, 1992) e formalistas (Nascimento, 1990; Dillinger, 1991) no início da década de 90, permitindo explicitar publicamente posições e questões que interessam a todos os estudiosos envolvidos na explicação do fenômeno linguagem. Recentemente, essa questão é retomada por Kato (1998) numa perspectiva integradora e harmônica.

Conseqüência natural do interesse pelos aspectos discursivo/funcionais da variação foi a extensão do modelo analítico variacionista a fenômenos fora do domínio oracional, submetendo ao rigor da análise quantitativa fenômenos como os processos de articulação de cláusulas e de articulação do próprio discurso. O estudo da variação de tempo-modo e conexão nas orações condicionais potenciais (Se a pessoa for virgem, tudo bem casa/Se eles estão ofendido, eles vão lá e joga e ganha) permite demonstrar o importante papel da variação na construção da estrutura retórica do discurso (Gryner, 1990; 1995; 1996). A análise da ordenação das cláusulas causais (Porque não tinha elevador eu desci a escada/ A maioria da classe média come em casa porque os restaurantes são proibitivos) (Paiva, 1992; 1995a; 1996b), das cláusulas temporais (Eu fico com remorso até de comer o pão, quando eu como? /Porque engraçado que, quando a gente viaja, a gente observa que as frutas de outros estados são totalmente diferentes) (Braga, 1995; no prelo) e o estudo das orações reduzidas de gerúndio (Agora é engraçado que você saindo do Brasil, a gente sente uma falta muito grande dessa parte de verduras.) (Braga, 1996) permitiram demonstrar a importância de princípios funcionalistas como o de iconicidade e o de distribuição de informação, além de fornecerem subsídios 
para a discussão do conceito de ordem marcada. O interesse pela ordenação de constituintes lingüísticos e pelas formas de combinação de cláusulas numa abordagem funcionalista tem levado o grupo a se voltar para os processos de gramaticalização, extraindo deste estudo consequiências teóricas importantes.

A função de algumas partículas e de estruturas próprias do discurso oral mereceu atenção especial. Os marcadores do discurso foram objeto de análise minuciosa, visando a identificar os diferentes papéis discursivos dessas partículas e a sua importância enquanto elementos de organização da sintaxe da fala (Silva \& Macedo, 1992; 1996; Silva et alii, 1996). Também voltado para a organização do discurso falado é o estudo de repetições como estratégias de processamento do texto (Roncarati, 1994). Ao se alargar o âmbito da variação, de forma a recobrir domínios cada vez mais amplos, salientou-se ainda a necessidade da análise de problemas ligados à tipologia de textos e à precisão de critérios distintivos de diferentes gêneros do discurso (Paredes da Silva, 1996; 1997a).

O Corpus Censo, dadas as suas especificidades de discurso monitorado, semi-informal, caracterizado por relação assimétrica entre os participantes do ato comunicativo, certamente limita, ou mesmo impossibilita, o estudo de alguns aspectos ligados a estilo de fala ou ao processo interacional. A incorporação de amostras de conversações espontâneas (Roncarati et alii, 1996; Paredes da Silva, 1997b) viabilizou (1) a verificação de condicionamentos como mudança de turno e relações entre os participantes da conversa sobre fenômenos lingüísticos variáveis e (2) a colocação de objetos de estudo próprios do processo interacional, envolvendo, por exemplo, as estruturas argumentais da conversação (Roncarati, 1994), formas de abertura de turnos (Macedo, 1994), a alternância entre tu e você para referência à $2^{\mathrm{a}}$. pessoa (Paredes da Silva, 1997b).

Como não poderia deixar de ser, o interesse pela variação e pela mudança culminou em hipóteses relativas à aquisição de processos variáveis no português enquanto L1 ou L2. Essa nova trilha, inaugurada com um conjunto significativo de estudos sobre o Português de Contato - variedade falada pelos diversos grupos étnico-lingüísticos da Reserva do Alto Xingu -, permitiu verificar a sistematicidade de alguns fenômenos variáveis em L1 e em L2. Citem-se a monotongação de [ey] e [ow], a queda de [r] medial e final, assimilação de [d] na seqüência -ndo, rotacismo (Mollica, 1997), preenchimento do sujeito (Duarte, 1995), estruturas de negação (Roncarati, 1997), aquisição de preposições (Gomes, 1997), formas de indeterminação do sujeito (Mollica 
et alii, 1995), marcadores discursivos (Macedo, 1997), realização da relação semântica de causalidade (Paiva, 1998) e gramaticalização da relação de contraste (Braga, 1998). ${ }^{6}$ A amostra do Português de Contato abriu espaço também para a discussão de alguns aspectos relativos às situações de contato lingüístico e à emergência de códigos simplificados, a partir do estudo de algumas das suas especificidades como a neutralização variável do traço de sonoridade (Paiva, 1997) e a realização da categoria de gênero (Macedo \& Lucchesi, 1997), a expressão das categorias de tempo e modo (Duarte, 1998b) e o uso do quantificador tudo como pluralizador (Loureiro, 1998).

Outra preocupação de membros do grupo PEUL tem sido a de construir elos entre a pesquisa básica e o ensino de línguas. O grupo tenta buscar nos resultados da pesquisa variacionista argumentos e diretrizes que permitam transformar a realidade do ensino/aprendizagem da norma escolar, seja pela discussão do preconceito lingüístico (Scherre, 1996b; 1996c), seja pela proposição de novas práticas pedagógicas (Mollica, 1995b; 1998).

3. A força da estrutura sobre a variação e a mudança lingüística

A focalização dos aspectos variáveis do português conduziu à depreensão de interdependências de todas as naturezas: (1) entre os componentes lingüisticos (fonético, fonológico, morfológico, sintático, semântico e lexical); (2) entre estes e outros componentes da linguagem (discursivo e pragmático) e, ainda, (3) entre os componentes lingüísticos e os aspectos não-lingüísticos (social, cognitivo e interacional), que envolvem o complexo fenômeno linguagem. As análises têm fornecido argumentos para a discussão de questões teóricas maiores, tais como identificação e entendimento das forças em competição, internas e externas; identificação dos caminhos e das motivações da mudança lingüística; identificação e proposição de princípios universais.

Raramente um fenômeno lingüístico variável se deixa explicar por meio de um único parâmetro ou por meio de um único princípio, mesmo que o fenômeno possa se encaixar no âmbito de seu próprio componente lingüístico. Mesmo fenômenos fonológicos, que mais freqüentemente se explicam à luz de restrições do próprio nível fonológico, não estão isentos de influências de natureza lexical e social. Fenômenos de natureza morfossintática, ou estritamente sintática, na maior parte das vezes, só se esclarecem na confluência de componentes diversos. 
Muitos dos fenômenos já relacionados ilustram essa interdependência entre diversos níveis/componentes, ou seja, o que Du Bois (1984) denominou de "motivações em competição". Tomemos alguns exemplos que, longe de esgotar a questão, apenas evidenciam a sua pertinência. As realizações do $\{\mathrm{S}\}$ pós-vocálico como palatal, alveolar, aspirada ou zero são controladas pela escala da sonoridade do contexto seguinte tanto no nível lexical (internamente à palavra) quanto no nível pós-lexical (na fronteira entre palavras), obedecendo de forma bastante regular ao ciclo da sonoridade e à lei do contato silábico. Além desse controle fonológico, o fenômeno está sujeito à influência de aspectos lexicais como a classe gramatical da palavra e, mesmo, de itens lexicais específicos.

A interseção exemplificada acima fornece subsídios importantes para a discussão da controvérsia neogramáticos/difusionistas que, no interior do PEUL, tem encontrado guarida e se enriquecido com novas evidências, fornecidas por estudos do português como L1 e como L2 (Mollica,1995a; Mattos e Mollica, 1992). Estudos exaustivos sobre a interface lexical da variação têm mostrado a relevância dos parâmetros frequiência e formalidade do item lexical em fenômenos de níveis diferentes: fenômenos de natureza sintática, como o (de)queísmo, e fenômenos de natureza fonético-fonológica como assimilação de ndo>no, queda da vibrante pós-vocálica em posição medial e final, queda da sibilante pós-vocálica em posição medial e final, monotongação de [ey] e [ow], aférese e prótese de segmentos sonoros.

A colaboração do nível fonológico para uma variação morfossintática fica explícita no uso variável das formas indicativas ou subjuntivas em frases imperativas. Embora o fenômeno seja um pouco sensível a fatores de natureza semântica (modalidade realis/irrealis), está também correlacionado a fatores de natureza fonológica. No caso específico dos verbos regulares da primeira conjugação, emerge a influência do traço de abertura da vogal precedente na forma verbal conjugada: se [+aberta], favorece o imperativo na forma indicativa (fala, cala, olha, volta, pega, espera); se [-aberta], favorece o imperativo na forma subjuntiva (mande, chame, tente, pense, tome, conte, analise, vire, procure, use) em um claro processo de assimilação ou, em outras palavras, de paralelismo fônico.

A alternância entre nós/a gente ilustra, de forma inequívoca, o jogo de forças entre o formal e o semântico na definição dos limites da variação e dos caminhos da mudança. Por um lado, a pressão do paralelismo lingüístico leva à repetição da forma nós ou de a gente em função da forma precedente. Por 
outro, a influência semântica da mudança de referente provoca alternância entre as formas, levando à diferenciação de uma forma em relação à que a antecede.

A imbricação entre o formal e o discursivo/funcional pôde ser constatada em alguns fenômenos de natureza sintática como, por exemplo, o (de)queísmo e a topicalização do sujeito. No primeiro fenômeno, associa-se à força do paralelismo (tendência à repetição da massa fônica de, particularmente a da preposição de) o efeito de fatores nitidamente funcionais: conexão entre construções distantes, analogia entre construções com equivalência semântico-estrutural e iconicidade. No caso da topicalização do sujeito, entram em jogo fatores de natureza formal, ainda que interpretáveis em termos psicolingüísticos, como número de sílabas do SN sujeito, presença de elementos interferentes entre o $\mathrm{SN}$ sujeito e presença de elementos pós-verbais e, também, fatores de natureza semântica - o caráter animado do referente -; e de natureza discursiva - status informacional do referente do SN sujeito.

Nos exemplos utilizados acima, ressaltou para vários fenômenos a ação controladora da variável paralelismo lingüístico (Scherre, 1988; no prelo), aspecto que gostaríamos de aprofundar. A recorrência e a sistematicidade do efeito dessa variável independente, para usar uma terminologia bem ao gosto dos variacionistas, a tornam forte candidata ao estatuto de um universal de processamento do uso lingüístico ${ }^{7}$. O paralelismo lingüístico em sentido lato, isto é, a repetição de elementos da mesma natureza ou de natureza semelhante, além de atuar de forma sistemática em fenômenos de todos os subsistemas lingüísticos, atua também em planos (ou níveis) lingüísticos diversos. Em outros termos, a harmonização entre as formas ou a tendência geral de formas gramaticais particulares ocorrerem juntas (Schffrin, 1981:55-6) pode ser observada (1) no plano discursivo - entre as formas no nível supra-oracional -, (2) no plano oracional - entre os constituintes maiores da oração -, (3) no plano sintagmático - entre elementos constitutivos do sintagma -, e (4) no plano da palavra - entre elementos da própria palavra ou entre elementos adjacentes de palavras que não formam constituinte.

No plano estritamente discursivo, a força do paralelismo se deixa observar nas construções de topicalização (Braga, 1986), na alternância nós e a gente

\footnotetext{
${ }^{7}$ A escolha da variável paralelismo como tônica das contribuições do PEUL, no plano das variáveis estruturais, decorre da necessidade de proceder a um recorte. A sistematicidade de diversas outras variáveis lingüísticas - saliência fônica, traço de animacidade, iconicidade e distribuição de informação - vem também despontando ao longo das muitas análises já realizadas.
} 
(Omena, 1996), na variação de tempo-modo e conexão nas condicionais potenciais (Gryner, 1990). Nos planos discursivo, oracional e sintagmático, esta força deixa-se entrever especialmente nos fenômenos de concordância de número (Scherre, 1988; 1991; Scherre \& Naro, 1991); no plano discursivo e no da palavra, manifesta-se na alternância entre para, pra e pa (Felgueiras, 1993); nos planos oracional e da palavra, deixa-se observar no (de)queísmo (Mollica, 1989; 1991a; 1991b); e no plano específico da palavra, deixa-se evidenciar nas variantes do modo imperativo (Scherre et alii, 1998).

A sistematicidade do efeito do paralelismo, já demonstrada também no estudo de fenômenos de muitas outras línguas, bem como em diversos outros fenômenos do português do Brasil, ${ }^{8}$ se reveste de importância capital por fornecer argumentos para a discussão de dois aspectos nucleares da teoria da variação: (1) o pressuposto da independência entre as diversas variantes de uma mesma variável dependente e da sua não interferência no efeito das variáveis independentes, caso haja interdependência entre as variantes (Sankoff \& Laberge, 1978); (2) o pressuposto de que necessidades comunicativas podem determinar a configuração da variação e da mudança lingüística.

A possibilidade da dependência entre duas ocorrências sucessivas de variantes de uma mesma variável dependente fica evidenciada no efeito positivo da variável independente paralelismo. É possível mostrar também que a influência do paralelismo pode repercutir no comportamento de variáveis sociais, especialmente entre paralelismo e anos de escolarização. A análise da concordância de número, observando separadamente dados com ocorrências sucessivas de variantes de uma mesma variável dependente (dados seriados) e dados sem ocorrências sucessivas de variantes de uma mesma variável dependente (dados não-seriados), permitiu verificar a interdependência entre as variáveis paralelismo e escolarização. A variável escolarização não se mostra relevante em dados em que a força interna do paralelismo se faz presente. Todavia, entre a variável paralelismo e as demais variáveis, quer lingüisticas

${ }^{8}$ A primeira referência a esta restrição em pesquisas variacionistas, no nível oracional, foi feita por Poplack (1980) em seus estudos sobre a concordância de número no SN, no espanhol de Porto Rico. Na literatura nacional, a primeira referência ao paralelismo deve ser atribuída a Omena (1978) no seu estudo sobre as formas pronominais variantes em função acusativa. Referências anteriores, sob a denominação de "efeito gatilho", especialmente na relação falante-ouvinte, são feitas, pela primeira vez, por Emmerich (1977).

${ }^{9}$ A hipótese de interdependência entre variáveis internas e variáveis sociais requer maiores testes, porque, de forma geral, tem-se advogado em favor da independência entre esses dois tipos de condicionamentos. 
quer sociais, nenhuma interferência significativa se fez notar. (Scherre \& Naro, $1992)^{9}$

A questão das pressões comunicativas sobre a variação e a mudança lingüística, retomada por Labov (1994:545-68), que incorpora resultados de análises desenvolvidas pelo PEUL, também pode ser rediscutida à luz do efeito da variável paralelismo. Enfatizando o papel do paralelismo linguiístico no funcionamento sincrônico das línguas, Labov (1994:550-86) considera que "a comunicação da informação não determina a configuração da variação e da mudança lingüística", o que significa dizer "que os falantes não são dominados pelas necessidades comunicativas quando escolhem uma variante particular na cadeia da fala", embora "a história das línguas reaja para preservar o significado em geral. Com base nesse pressuposto, Labov desenvolve um modelo de mudança no qual estabelece que "não é o desejo de ser entendido, mas sim a conseqüência de problemas de interpretação é que influencia a mudança lingüística".

As reflexões de Labov acerca das implicações anti-funcionais da variável paralelismo são discutidas no seio do PEUL (Naro, 1996), com base no argumento de que é fundamental distinguir o status dos diferentes tipos de fenômenos variáveis (variação estável, mudança de longa duração ou mudança em progresso) para situar com precisão o papel do paralelismo e a importância do efeito das necessidades comunicativas na variação e na mudança lingüística. Todos os fenômenos apresentados por Labov para subestimar a força do aspecto funcional na variação lingüística são do tipo variação estável, como ele próprio coloca, ou são fenômenos de mudança lenta na sua fase final, nos quais a força do paralelismo é mais saliente. Há de se considerar, todavia, que, em fenômenos de mudança que se encontram em sua fase intermediária, ou seja, no meio do ciclo funcional (Givón, 1995), variáveis de natureza informacional (no sentido mais amplo do termo) exercem um papel fundamental na configuração do espectro de variação. As mudanças em sua fase final, estas, sim, são menos susceptíveis à influência de variáveis de natureza informacional diversa, ou seja, são mais susceptíveis à influência do paralelismo. A questão não pode ser colocada, portanto, em termos de afirmação ou negação total de restrições comunicativas sobre a variação. As evidências existentes são todas consistentes "com a hipótese de que o grau de funcionalidade de uma variável lingüística depende de seu lugar no ciclo funcional" (Naro, 1996).

\section{Contraparte social da variação e da mudança}


É um truísmo dizer que os estudos sociolingüísticos contribuem não só para tornar evidente a sistematicidade de variedades do português, especialmente as não-cultas, como também para fornecer novos elementos à discussão do binômio homogeneidade/heterogeneidade. Mais problemática, no entanto, é a identificação dos parâmetros sociais correlacionados à variação e à mudança lingüística.

Uma busca ininterrupta à contraparte social da variação e aos índices extralingüísticos dos processos de mudança permitiu a depreensão do efeito não só de aspectos sociais adstritos ao falante (como sexo e idade) ou por ele adquiridos (como local de moradia, escolaridade) como também daqueles que envolvem os sistemas de representação vigentes no grupo social (como mercado lingüístico ou sensibilidade lingüística), ou a relação do falante com veículos de comunicação como a televisão. Foi possível demonstrar regularidades salientes em relação ao efeito dessas variáveis sociais sobre fenômenos de variação e mudança lingüística (Silva \& Paiva, 1996).

Dadas as características da sociedade brasileira, na qual um imenso contigente da população é excluído do direito à escolarização formal, a variável escolaridade suplanta as demais, moldando, em grande parte, a heterogeneidade lingüística que se pode constatar no uso do português carioca. A escolarização continuada, refinando a consciência lingüística e insistindo na necessidade de padronização, favorece o emprego de determinadas variantes lingüísticas, em especial das que estão sujeitas a uma avaliação social positiva. Assim, retomando alguns dos fenômenos já apresentados, os falantes mais escolarizados (com $2^{\circ}$ grau) apresentam maior presença de marca de plural em todos os elementos do SN, maior índice de preposições a e para com o verbo ir, menor freqüência de rotacização do [1] nos grupos consonantais. Pelo menos em duas das variações citadas acima (concordância nominal e rotacismo), as variantes se distribuem nitidamente pelo binômio forma padrão/forma nãopadrão, sendo objeto de correção sistemática do ensino. Em síntese, a ocorrência das variantes lingüísticas prestigiadas socialmente está correlacionada de forma saliente à variável escolaridade.

É preciso salientar no entanto que, de um ponto de vista estatístico, a variável escolaridade atua igualmente sobre fenômenos menos marcados socialmente, como a monotongação de [ey], uso de artigo diante de possessivo ou uso de seu/dele, que não são alvos explícitos de um ensino regular. Este fato leva a crer que a escola, além de fazer uma pressão direta sobre o uso lingüístico, atua também de forma indireta, ao iniciar e inserir o falante em uma 
modalidade mais rígida e mais homogênea como a escrita. É possível também que a influência da variável escolaridade reflita, na verdade, a ação da variável classe social. Se assim for, as conseqüências são ainda mais perversas: não se modificam variantes lingüísticas, mas, sim, se excluem os indivíduos que não possuem determinadas variantes lingüísticas.

A variável sexo estabelece fronteira bastante nítida entre homens e mulheres, com as últimas demonstrando maior sensibilidade ao valor simbólico da variação. As mulheres, diferentemente dos homens, fazem mais concordância nominal, usam mais ir a/para do que ir em e rotacizam menos o [1] dos grupos consonantais. Esse apego do sexo/gênero feminino às variantes lingüísticas mais prestigiadas se faz sentir não apenas na produção, mas também na sua atitude em relação à variação, julgando de forma mais rígida o binômio padrão/não padrão.

A variável idade, por sua vez, forneceu índices para hipotetizar alguns processos de mudança em curso no português falado no Rio de Janeiro. Assim, a forma a gente, segundo a distribuição de estatísticas por faixas etárias, tende a se espraiar e a se implementar no sistema. Da mesma forma, verifica-se a perda do pronome possessivo seu, cada vez mais restrito à fala de pessoas mais velhas, e a progressiva implementação de dele entre falantes mais jovens. Além disso, um padrão nítido de distribuição de variantes lingüísticas pode ser constatado a partir da variável idade: os falantes mais jovens se mostram menos compromissados com a correção lingüística, valendo-se, em maior grau, das variantes menos prestigiadas.

Um aspecto crucial com relação ao efeito de variáveis sociais é o da independência do efeito de cada uma delas. A análise minuciosa das possíveis interações entre dois ou mais parâmetros sociais revela que o efeito de uma pode depender, pelo menos em parte, do efeito de outra. Tal é o caso, por exemplo, da variável sexo cujo efeito é, para muitos fenômenos, função da variável idade. Enquanto mulheres e homens mais velhos se distinguem quanto ao uso lingüístico, os jovens do sexo masculino e do sexo feminino tendem a se nivelar lingüisticamente.

Além dos padrões relativos à escolaridade, idade e sexo - variáveis sociais convencionais - outros vão emergir na análise de outros parâmetros externos associados à variação e mudança lingüísticas. Fatores como a inserção do falante no mercado ocupacional, o grau de exposição à mídia e a sensibilidade lingüística, testados empiricamente, se revelaram vetores importantes de 
explicação da diversificação lingüística em uma comunidade de fala. A pressão social na linguagem, como se pode prever, envolve também os sistemas de representação acerca da linguagem e os estereótipos homogeneizantes veiculados pelos meios de comunicação de massa, em especial, a televisão. As variantes lingüísticas prestigiadas predominam entre falantes mais bem cotados no mercado ocupacional, mais expostos à mídia e mais atentos às diferenças de linguagem.

Correlações interessantes entre essas variáveis que reproduzem sistemas de valores e as variáveis mais convencionais também puderam ser sugeridas. Em alguns fenômenos, pôde ser observada, entre falantes do sexo feminino, uma atuação conjunta das variáveis mercado ocupacional e escolarização. Entre falantes do sexo masculino, no entanto, às vezes, o efeito de mercado ocupacional neutraliza o de escolarização, quando as duas variáveis são analisadas conjuntamente. $\mathrm{O}$ efeito da exposição à mídia também é mais transparente entre as mulheres.

A busca de variáveis sociais não convencionais para o entendimento da variação linguiística numa sociedade tão complexa como a brasileira, em que a categorização por classe social segundo parâmetros como renda, local de moradia, escolarização e profissão não é claramente delimitada, tem motivado o controle de aspectos mais sutis da ambientação material e cultural dos indivíduos e do seu grau de integração aos valores veiculados pelos meios de comunicação de massa. Concebidas na forma de escalas que controlam a relação quantitativa e qualitativa dos falantes com os produtos culturais (como mídia televisiva e escrita, cinema, teatro e outros), a sua posse de bens materiais disponíveis no mundo moderno (apartamentos, carros, telefones, viagens, etc.) e as suas expectativas em relação ao futuro, variáveis como bens materiais, bens culturais e motivação vêm insinuando uma outra forma de exame de variação sociolingüística. A relevância dessas variáveis mais refinadas pôde ser verificada, numa primeira análise, nos processos variáveis de concordância de número (Naro \& Scherre, 1991; 1993a; 1996b), nos processos referentes aos grupos consonantais (rotacismo de [1] e queda de [r]) e na supressão de [d] na sequiência ndo (Silva, 1994; Lima, 1994; Fundo, 1994; Paiva, 1994; Paiva \& Gomes, 1998)).

Conjugadas às variáveis mais convencionais como idade, sexo e escolarização, essas variáveis mais refinadas permitem detectar tendências divergentes no interior da mesma comunidade de fala. No que tange aos fenômenos de concordância de número, observa-se, na comunidade de fala 
carioca, grupos em momentos e/ou direções distintas: para uns, há indícios de variação estável; para outros, vislumbra-se perda da concordância e, para alguns outros, entrevê-se processo de aquisição (Naro \& Scherre, 1991; 1993b; 1996b).

Revela-se, portanto, estreita correlação entre a complexidade social e os processos de variação.

\section{Considerações finais}

Estas palavras finais não configuram uma conclusão, mas, antes, uma breve colocação de novas perspectivas. Na forma como procuramos delinear ao longo deste artigo, o grupo PEUL procurou não apenas desvendar o universo de variação da fala não culta do Rio de Janeiro como também ampliar o domínio da Sociolingüística quantitativa por meio da incorporação de outros paradigmas interpretativos da variação e da mudança lingüística. Na medida em que se solidificaram técnicas de análise empírica, novas questões foram abrindo espaço para a investigação de outros objetos de estudo e para um maior refinamento das variáveis estruturais e sociais associadas à variação e à mudança.

Um longo caminho percorrido e alguma experiência adquirida no percurso servem, por sua vez, como ponto de partida para a colocação de outras questões relativas, principalmente, à implementação e encaixamento da mudança lingüística. Essas novas vertentes constituem, no momento, o núcleo de interesse do grupo que passa a buscar no estudo da mudança em tempo real as evidências necessárias para a confirmação de hipóteses formuladas a partir de estudos em tempo aparente. Os dados coletados pelo PEUL já fazem 20 anos, o espaço de uma geração. Novos dados serão gravados para levarmos a cabo uma análise em tempo real. O PEUL espera, dessa forma, trazer novas contribuições à compreensão dos caminhos trilhados pelo português brasileiro e a uma teoria mais geral da mudança lingüística.

REFERÊNCIAS BIBLIOGRÁFICAS

Agullera, V. de A. (org.) (1998) A geolingüística no Brasil-Caminhos e perspectivas. Londrina: UEL.

Almeida, N. L. F. \& Z. de O. N. CARNeIRo (1998) A língua portuguesa no semiárido baiano. IV Congresso de Estudos Lingüísticos e Literários. Feira de Santana: UEFS. 
Amaral, A. (1920) O dialeto caipira. São Paulo: O Livro.

Aragão, M. do S. S. de \& M. E. SoARes. (orgs.) (1996) A linguagem falada em Fortaleza. Fortaleza: Universidade Federal do Ceará.

BAXTER, A. N. \& D. Lucchesı. (1997) A relevância dos processo de pidginização e crioulização na formação da língua portuguesa no Brasil. Estudos lingüísticos e literários ( . $^{\circ}$ especial). Salvador, Universidade Federal da Bahia: 65-83.

Bortoni, S. M. R. (1984) The urbanization of rural dialect speakers: a sociolinguistic study in Brazil. Cambridge: Cambridge University Press.

Braga, M. L. (1986) Construções de tópico de discurso. Relatório final de pesquisa: Projeto subsídios do "Projeto Censo" à educação, III. Rio de Janeiro: UFRJ: 393-453 (inédito).

(1987) Esta dupla manifestação de sujeito, ela é condicionada lingüisticamente. In: Estudos lingüísticos. Anais de seminários do GEL, XIV, Campinas, UNICAMP: 106-15.

(1991) As sentenças clivadas no português falado no Rio de Janeiro.

Organon, 18 (5) - A variação no português do Brasil, Porto Alegre:

UFRGS-Instituto de Letras: 109-25.

(1995) As orações de tempo no discurso oral. In: I.G.V. Koch \& M. L.

Braga (orgs.) Cadernos de estudos lingüísticos, 28. Campinas: UNICAMP/IEL: 85-97.

(1996) Processos de redução: o caso das orações de gerúndio. In: I. G. V. Koch (org.) Gramática do Português falado, VI: Desenvolvimentos. Campinas: Editora da UNICAMP/FAPESP: 231-52.

(1997) Discurso e abordagens quantitativas. Alfa, 41 (n. $\left.{ }^{\circ} \mathrm{esp}\right)$. São Paulo: UNESP: 41-56.

(no prelo). The articulation of clauses: time.

(1998) A codificação de contraste no português de contato: um processo de gramaticalização. Estudos Lingüísticos, 27. Anais do Seminário do GEL. São José do Rio Preto: 111-9.

BRAGA, M. L. et alii. (1991) Results of an integrated sociolinguistic study. In: F. G. de Matos; S. M. Bortoni \& J. Fishman (eds.) International journal of the sociology of language - Sociolinguistics in Brazil. Berlin: Mouton: 153-74.

Braga, M. L. \& M. C. Mollica. (1986) Marcas segmentais e/ou suprasegmentais entre sujeito e o predicado e sua função discursiva. O histórico e o discursivo. Uberaba, Série Estudos, 12: 24-40.

Brandão, S. F. \& S. R. VIEIRA (1998) Aspectos morfossintáticos da fala de comunidades pesqueiras: um estudo variacionista. In: S. GRoBE \& K. Zimmermann (eds.) <<Substandard $>>$ e mudança lingüística no 
português do Brasil. Frankfurt am Main: TFM: 227-54.

Callou, D. M. I. (1998) Um estudo em tempo real em dialeto rural brasileiro: questões morfossintáticas. In: S. GroBe \& K. Zimmermann (eds.) $<<$ Substandard $>>$ e mudança no português do Brasil. Frankfurt am Main: TFM: 255-72.

Callou, D. M. I., N. Omena \& V. L. Paredes da Silva (1991) Cadernos de estudos lingüísticos, 20 - Sociolingüística. IEL/UNICAMP: 17-2.

CÂmara JR., J. M. (1975) Dispersos. Rio de Janeiro: Fundação Getúlio Vargas. Careno, M. F. (1992) A linguagem rural do Vale do Ribeira: a voz, a vez das comunidades negras. Assis: Universidade Estadual Paulista. Tese de Doutorado, inédito.

CAstilho, A. T. de (1990) Apresentação do projeto da gramática do português falado. In: A. T. CAstilho (org.) Gramática do português falado. Campinas: UNICAMP/FAPESP: 7-27.

(1998) Para a história do português brasileiro. Primeiras idéias. São Paulo: Humanitas, I.

Cerqueira, V. C. (1990) A forma dele na indicação de posse e as mudanças no sistema pronominal. Campinas: UNICAMP. Dissertação de Mestrado, inédito.

CorrêA, V. R. (1998) Oração relativa: o que se fala e o que se aprende no português do Brasil. Campinas: UNICAMP. Tese de Doutorado, inédito.

Cunha, C. (1989) Objetivos do projeto NURC. In: A. T. de Castilho (org.) Português culto falado no Brasil. Campinas: UNICAMP: 11-14.

Cyrino, S. M. L. (1997). O objeto nulo no português do Brasil - um estudo diacrônico. Londrina: UEL.

Dillinger, M. (1991) Forma e função na lingüística. D.E.L.T.A., 7(1): 395-40.

DuARTE, M. E. L. (1995) A perda do princípio "evite pronome" no português brasileiro. Campinas: UNICAMP. Tese de Doutorado, inédito. (1997) Aquisição do sujeito pronominal em L2. In: C. RonCARATI \& M. C. Mollica. Variação e aquisição. Rio de Janeiro: Tempo Brasileiro: 4364.

(1998) O sujeito nulo no português do Brasil: de regra obrigatória a regra variável. In: S. GroBe \& K. Zimmermann (eds.) Substandard e mudança lingüística no português do Brasil. Frankfurt am Main: TFM: 189-202.

Du BoIs, J. W. (1984) Competing motivations. In: J.Haiman. Iconicity in syntax. Amsterdam: John Benjamins: 342-65.

EMMERICH, C. (1977) Um traço propulsor numa língua de contato. In: Anais do $2^{\circ}$ Encontro Nacional de Lingüística. Rio de Janeiro: PUC: 393-9. (1984) A língua de contato no Alto Xingu - origem, forma e função. Rio 
de Janeiro: UFRJ. Tese de Doutorado, inédito.

FelgueIras, C. M. (1993) Análise da variação no uso da preposição PARA. Rio de Janeiro: UFRJ, Dissertação de Mestrado, inédito.

FERNANDES, M. (1996) Concordância nominal na região sul. Florianópolis: UFSC. Dissertação de Mestrado, inédito.

FERREIRA, C (1994) Remanescentes de um falar crioulo brasileiro. Diversidade do português do Brasil - Estudos da dialetologia rural e outros. Salvador: Centro Editorial e Didático da UFBA: 21-32.

FERreira, C. et alii. (1994) Diversidade do português do Brasil - Estudos da dialetologia rural e outros. Salvador: Centro Editorial e Didático da UFBA.

FIORETTI, M. T. G. (1996) Alternância no uso dos verbos existenciais em português. Rio de Janeiro, UFRJ. Dissertação de Mestrado, inédito.

Fundo, K. H do (1994) Distribuição e interseção das novas variáveis. Boletim da ABRALIN, 15. Salvador, UFBA: 256-61.

Givón, T. (1995) Functionalism and grammar. Amsterdam: John Benjamins.

Gomes, C. A. (1996) Aquisição e perda de preposições no português do Brasil. Rio de Janeiro: UFRJ. Tese de doutorado, inédito.

(1997) Processos variáveis e aquisição de preposição em L2. In: C. Roncarati \& M. C. Mollica (orgs.) Variação e aquisição. Rio de Janeiro: Tempo Brasileiro: 103-16.

Gonçalves, C. A. V. (1993). Aférese e prótese: verso e reverso morfológico. Rio de Janeiro: UFRJ. Dissertação de Mestrado, inédito.

GRYNER, H. (1990) Variação de tempo-modo e conexão nas orações condicionais em português. Rio de Janeiro: UFRJ. Tese de Doutorado, inédito.

(1995) Graus de vinculação nas cláusulas condicionais. In: I.G.V. КocH \& M. L. Braga (orgs.) Cadernos de estudos lingüísticos, 28. Campinas, UNICAMP/IEL: 69-83.

(1996) Variação modal como estratégia argumentativa. In: A. T. MACEDO \& C. Roncarati \& M. C. Mollica (orgs.) Variação e discurso. Rio de Janeiro: Tempo Brasileiro: 113-27.

Guy, G. R. (1989) On the nature and origins of popular Brazilian Portuguese. In: Estudios sobre Español de América y Lingüistica Afroamericana. Bogotá: Intituto Caro Y Cuervo: 226-44.

HorA, D. da (1998) Variação lingüística no Estado da Paraíba: aspectos fonéticos-fonológicos In: S. GroBe \& K. Zimmermann (eds.) Substandard e mudança lingüística no português do Brasil. Frankfurt am Main: TFM: 315-328.

Holm, J. (1991) Vernacular Brazilian Portuguese: a semi-creoule. In: E. D'ANDRADE \& A. Кıнм (orgs.) Actas do Colóquio sobre "crioulos de base lexical portuguesa”. Lisboa: Colibri: 37-6. 
Isensee, D. M. (1964) O falar de Mato Grosso (Bahia): fonêmica - aspectos da morfo-sintaxe e do léxico. Brasília: UnB. Dissertação de Mestrado, inédito. Jeroslow, E. H. M. (1974) Rural Cearense Portuguese: a study of one variety of nonstandard Brazilian speech. Cornell University. Dissertation.

(1975) Creole characteristics in rural Brazilian Portuguese. Unpublished paper presented at the International Conference on Pidgins and Creoles. University of Hawaii.

Kato, M. A. (1998) Formas de funcionalismo na sintaxe. D.E.L.T.A., 14 (n. ${ }^{\circ}$ especial): $145-68$.

Labov, W. (1975) Sociolinguistic patterns. Philadelphia: University of Pennsylvania Press.

(1994) Language and Society, 20. Principles of Linguistic Change Internal Factors. Cambridge: Blackwell.

LuCheSI, D. \& A T. de MACEDO (1997) Variação na concordância de gênero no Português de Contato do Alto Xingu. Papia; revista de crioulos de base ibérica, 9. Brasília: Universidade de Brasília: 20-36.

Lemle, M. \& A. J. NARo (1977) Competências básicas do português. Relatório final de pesquisa apresentado às instituições patrocinadoras Fundação Movimento Brasileiro de Alfabetização (MOBRAL) e Fundação Ford. Rio de Janeiro.

LimA, J. D’ Arc de M. (1992) Difusão lexical na vibrante final. Rio de Janeiro: UFRJ, Dissertação de Mestrado, inédito.

LiMA, L. de (1994) Descrição e categorização das novas variáveis. Boletim da ABRALIN, 15. Salvador: UFBA: 250-55.

Loureiro, F. C. (1998) O uso de tudo como pluralizador no Português de Contato. Rio de Janeiro, UFRJ. Dissertação de Mestrado, inédito.

Macedo, A. T. de (1994) Como iniciar o turno. In: M. C. Mollica \& L. P da M. LOPES (org.) Tempo Brasileiro, 117. Linguagem, interação e cognição. Rio de Janeiro: Tempo Brasileiro: 45-54.

(1997) Aquisição de marcadores em primeira e em segunda língua. In: C. Roncarati \& M. C. Mollica (orgs.) Variação e aquisição. Rio de Janeiro: Tempo Brasileiro: 43-64.

Marroquim, M. (1945) A língua do nordeste - Alagoas e Pernambuco. São Paulo: Nacional.

Martelotta, M. E et alii (1996) (orgs.) Gramaticalização no português do Brasil. Rio de Janeiro: Tempo Brasileiro.

Mattos e SiLva, R. V. (1996) (org.) Carta de Caminha-Testemunho lingüístico de 1500. Salvador: UFBA.

Mattos, P. B. \& M. C. de M. Mollica (1989) Dois processos de assimilação fonológica no português falado semi-espontâneo do Rio de Janeiro. 
Relatório final do projeto Mecanismos funcionais do uso da língua. Rio de Janeiro: UFRJ, inédito.

(1992) Pela conjugação das abordagens variacionista e difusionista. Revista de estudos da linguagem, 1. Belo Horizonte: UFMG: 53-64.

Mollica, M. C. de M. (1989a) Queísmo e Dequeísmo em português. Rio de Janeiro, UFRJ. Tese de Doutorado, inédito.

(1989b) Influência de fatores de processamento na variação em português. In: F. TARALlo (org.) Fotografias sociolingüísticas. São Paulo: Ática: 283-300.

(1991a) (De) queísmo: variação em conexões intersentenciais. Organon, 18 (5). A variação no português do Brasil. Porto Alegre:UFRGS - Instituto de Letras: 37-51.

(1991b) Processing and morpho-semantic effects in complementation in Brazilian Portuguese. Language Variation and Change, 3 (3). Cambridge University Press: 265-74.

(1993) Intervalos entre o silêncio e a fala e suas conseqüências na escrita. Cadernos de Letras, 9. Rio de Janeiro: UFRJ: 143-9.

(1994a) Mecanismos prosódico-interativos na comunicação. In: M. C. Mollica \& L. P da M. Lopes (org.) Tempo Brasileiro,117. Linguagem, interação e cognição. Rio de Janeiro: Tempo Brasileiro: 55-60.

(1994b) Funções diferentes de "variantes" ou equivalência semânticofuncional em variação. Boletim da ABRALIN,15. Salvador, UFBA: 74-79. (1995a) (De) que falamos? Rio de Janeiro: Tempo Brasileiro.

(1995b) Aplicação pedagógica de estudos variacionistas. In: L.P. da M.Lopes \& M. C. Mollica (orgs.) Espaços e interfaces da lingüística e da lingüística aplicada. - Cadernos didáticos, 17. Rio de Janeiro: UFRJ: 49-57.

(1996a) A regência do verbo $i r$ de movimento. In: G. M. de O. e Silva \& M. M. P. Scherre (orgs.) Padrões sociolingüísticos - análises de fenômenos variáveis do português falado no Rio de Janeiro. Rio de Janeiro: Tempo Brasileiro.

(1996b) Supra-segmentos de fronteira: principais causas e funções. In: A. T. Macedo \& C. Roncarati \& M. C. Mollica (orgs.) Variação $e$ discurso. Rio de Janeiro: Tempo Brasileiro: 129-47.

(1997) Padrões fonológicos variáveis em aquisição. In: C. RonCARATI \& M. C. Mollica (orgs.) Variação e aquisição. Rio de Janeiro: Tempo Brasileiro: 33-64.

(1998) Influência da fala na alfabetização. Rio de Janeiro: Tempo Brasileiro.

MollicA, M. C. de M. et alii (1995) Contato linguiístico e aquisição do 
português. Revista Internacional de Língua Portuguesa (RILP), 14. Lisboa: Associação das Universidades de Língua Portuguesa: 119- 27. Mollica, M. C. de M. \& M. da C. Paiva (1991) Restrições estruturais atuando na relação entre $[1] /[\mathrm{r}]$ e [r] 0 em grupos consonantais em português. Boletim da ABRALIN, 11(1). São Paulo, UNICAMP, Campinas: 181-89.

(1993) Grupos consonantais: da gênese ao português contemporâneo. Terceira margem, 1. Rio de Janeiro, Faculdade de Letras, UFRJ: 136-140. Monteiro, C. do R. (1933) A linguagem dos cantadores. Rio de Janeiro. Tese apresentada em concurso à Congregação do Colégio Pedro II.

Moura, M. D. (1997) (org.) Variação e ensino. Maceió: EDUFAL.

NARO, A. J. (1981) The social and structural dimensions of a syntactic change. Language, 57: 63-98.

(1996) The functional nature of variation. XXV New ways of analyzing variation (NWAVE) - Universidade de Nevada/Las Vegas, inédito.

NARO, A. J. \& M. M. P. SchERRE (1991) Variação e mudança lingüística: fluxos e contrafluxos na comunidade de fala. Cadernos de estudos lingüísticos,20. Sociolingüística. IEL/UNICAMP: 9-15.

(1993a) Sobre as origens do português popular do Brasil. D.E.L.T.A., 9 (n. ${ }^{\circ}$ especial): 437-54.

(1993b) Flows and counter flows in variation and change. XXII New ways of analyzing variation (NWAVE) - Universidade de Ottawa/Ottawa, inédito.

(1996a) Disfluencies in the Analysis of Speech Data. Language Change and Variation and Change, 8. Cambridge University Press: 1-12.

(1996b) Contact with media and linguistic variation. In: J.ARNOLD et alii (ed.) Sociolinguistic Variation - Data, Theory and Analysis - Selected Papers from NWAV23 at Stanford, Stanford University: 223-8. .

(1998) A hierarquização do controle da concordância no português moderno e medieval: o caso de estruturas de sujeito composto. Comunicação apresentada no Colóquio Internacional- projetos de investigação lingüística sobre o português do Brasil. Berlim.

(no prelo) Variable concord in Portuguese: the situation in Brazil and Portugal. In: J. McWHORTER (ed.) Current issues in pidgin and creole linguistics. Amsterdam: John Benjamins.

Naro, A. J. \& S. J. Votre (1992) Mecanismos funcionais do uso da língua função e forma. D.E.L.T.A., 8(2): 285-90.

NASCEnTES, A. (1953) O linguajar carioca. Rio de Janeiro: Organização Simões.

NASCimEnTo, M. (1990) Teoria gramatical e "mecanismos funcionais do uso da língua".D.E.L.T.A., 6(1): 83-98.

NinA, T. de J. C. (1980). Concordância nominal/verbal do analfabeto na micro- 
região de Bragantina. Rio Grande do Sul: PUC. Dissertação de Mestrado, inédito.

Nunes, J. (1995) Ainda o famigerado SE. D.E.L.T.A., 11 (2): 201-40.

Omena, N. P. de. (1978) Pronome pessoal de terceira pessoa: suas formas variantes em função acusativa. Rio de Janeiro: PUC. Dissertação de Mestrado, inédito.

(1987) A alternância entre nós e a gente na função de sujeito. In: Estudos lingüísticos - Anais de seminários do GEL, XIV. Campinas: UNICAMP: 94-105.

(1996) A referência variável da primeira pessoa do discurso no plural. In: G. M. de O. e Silva \& M. M. P. Scherre. (orgs.) Padrões Sociolingüísticos - Análises de fenômenos variáveis do português falado no Rio de Janeiro. Rio de Janeiro, Tempo Brasileiro: 183-215.

Pagotto, E. G. (1992) A posição dos clíticos em português - um estudo diacrônico. Campinas: Unicamp. Dissertação de Mestrado, inédito.

PAIVA, M. da C. (1992) Ordenação das cláusulas causais: forma e função. Rio de Janeiro: UFRJ. Tese de Doutorado, inédito.

(1994) Nova abordagem de velhos fenômenos. Boletim da ABRALIN,15. Salvador, UFBA: 262-67.

(1995a) Cláusulas causais: iconicidade e funcionalidade. In: I. G. V. Koch \& M. L. Braga (orgs.) Cadernos de estudos lingüísticos,28. Campinas: UNICAMP/IEL: 59-68.

(1995c) Empregos do PORQUE no discurso oral. D.E.L.T.A., 11(1): 2739.

(1996a) A supressão das semivogais nos ditongos decrescentes. In: G.

M. de O. e Silva \& M. M. P. Scherre (orgs.) Padrões Sociolingüísticos

- Análises de fenômenos variáveis do português falado no Rio de Janeiro. Rio de Janeiro: Tempo Brasileiro: 217-36.

(1996b) Aspectos semânticos e discursivos da relação de causalidade. In: A. T. Macedo \& C. Roncarati \& M. C. Mollica Variação e discurso. (orgs.) Rio de Janeiro: Tempo Brasileiro: 63-74.

(1997) Variação e aquisição do traço sonoridade. In: C. RonCARATI \& M. C. Mollica (orgs.) Variação e aquisição. Rio de Janeiro: Tempo Brasileiro: 15-32.

(1998) Da parataxe à hipotaxe: uma trajetória do Português de Contato. Estudos Lingüísticos, 27. Anais do Seminário do GEL. São José do Rio Preto: 120-9.

\& C. A Gomes (1998) Pressões sociais da variação e da mudança. Comunicação apresentada no XIII Encontro Nacional da ANPOLL, Campinas. 
Paredes Da Silva, V. L. (1988) Cartas cariocas: A variação do sujeito na escrita informal. Rio de Janeiro, UFRJ. Tese de Doutorado, inédito.

(1992) A relevância dos fatores internos. In: M. C. Mollica (org.) Introdução à sociolingüística variacionista. Cadernos Didáticos. Rio de Janeiro: FL/UFRJ: 33-7.

(1993) Subject omission and functional compensation: evidence from written Brazilian Portuguese. Language Variation and Change,5. Cambridge: Cambridge University Press: 35-49.

(1994) Marcas de oralidade na escrita como sinais de interação. In: M. C. Mollica \& L. P da M. Lopes (orgs.) Tempo Brasileiro, 117 - Linguagem, interação e cognição. Rio de Janeiro: Tempo Brasileiro: 67-74.

(1996) Quando escrita e fala se aproximam: pronomes de terceira pessoa em cartas pessoais. In: A. T. Macedo \& C. Roncarati \& M. C. Mollica (orgs.) Variação e discurso. Rio de Janeiro: Tempo Brasileiro: 63-74.

(1997a) Forma e função nos gêneros de discurso. Alfa, 41 (n. ${ }^{\circ}$ esp.). São Paulo: UNESP: 79-98.

(1997b) A variação na referência à $2^{a}$ pessoa no português carioca. Relatório final do projeto PEUL 2, inédito.

PInTo, I. I. (1996) A variação entre tudo e todo(a)(s) no português informal carioca. Rio de Janeiro: UFRJ. Dissertação de Mestrado, inédito.

Poplack, S. (1980) The notion of the plural in Puerto Rico Spanish: competing constraints on /s/ deletion. In: W. LABOv (eds.) Locating language in time and space. Philadelphia: University of Pennsylvania: 55-67.

Ramos, J. M. (1997) O uso das formas você, ocê e cê no dialeto mineiro. In: D. da Hora (org.) Diversidade lingüística no Brasil. João Pessoa: Idéia: 46-60.

Novos clíticos no português brasileiro: Projeto Integrado CNPq. Belo Horizonte: UFMG, 1998-2000.

Roberts, I. \& M. A. Kato (1993) (orgs.) Português brasileiro - uma viagem diacrônica. Campinas, SP: Editora da UNICAMP.

Rodrigues, A. N. (1974) O dialeto caipira na região de Piracicaba. São Paulo: Ática.

RonCARATI, C. (1994) Repetição e saliência em interações dialogadas. In: M. C. Mollica \& L. P da M. Lopes (orgs.) Tempo Brasileiro - Linguagem, interação e cognição, 117. Rio de Janeiro: Tempo Brasileiro: 75-90.

(1996) A negação no português falado. In: A. T. MACEDo, C. RonCARATI \& M. C. Mollica (orgs.) Variação e discurso. Rio de Janeiro: Tempo Brasileiro: 97-112.

(1997) Ciclo aquisitivos da negação. In: C. Roncarati \& M. C. Mollica (orgs.) Variação e aquisição. Rio de Janeiro: Tempo Brasileiro: 03-16. 
Roncarati, C et alii (1996) Banco de dados interacionais. Rio de Janeiro: Pósgraduação da Faculdade de Letras, UFRJ.

SANKOFF, D. (1988a) Sociolinguistics and syntactic variation. In: F. J. NEWMEYER (ed.) Linguistics: the Cambridge survey: IV (Language: the socio-cultural context). New York: Cambridge University Press: 141-60.

(1988b) Variable rules. In: U.Ammon \& N. Dittmar \& K. J. Mattheier (eds.) Sociolinguistics - An international handbook of the science of language and society. Berlin/New York: Walter de Gruyter: 984-98.

SAnKoff, D. \& S. Laberge (1978) Statistical dependence among successive occurrences of a variable in discourse. In: D. SANKofF (ed.) Linguistic variation: models and methods. New York: Academic Press: 119-26.

SCHFFrin, D. (1981)Tense variation in narrative. Language, LSA, 57(1): 45-62. SchERRE, M. M. P. (1988) Reanálise da concordância de número em português. Rio de Janeiro, UFRJ. Tese de Doutorado, inédito.

(1989) Sobre a saliência fônica na concordância nominal em português. In: F. TARAllo (org.) Fotografias Sociolingüísticas. São Paulo: Pontes: 301-32.

(1991) A Concordância de número nos predicativos e particípios passivos. Organon, 18 (5) - A variação no português do Brasil. Porto Alegre: UFRGS-Instituto de Letras: 52-70.

(1994) Aspectos da concordância de número no português do Brasil. Revista Internacional de Língua Portuguesa (RILP), 12. Lisboa: Associação das Universidades de Língua Portuguesa: 37-49. (1996a) Sobre a influência de três variáveis relacionadas na concordância nominal em português. In: G. M. de O. e Silva \& M. M. P. Scherre (orgs.) Padrões Sociolingüísticos - Análises de fenômenos variáveis do português falado no Rio de Janeiro. Rio de Janeiro: Tempo Brasileiro: 85-117.

(1996b) Pesquisa e ensino: modelos de análise em debate - o modelo variacionista. In: Pesquisa e Ensino de Língua: Contribuições da Sociolingüística - Anais do II Simpósio Nacional do GT Sociolingüística da ANPOLL. UFRJ, Faculdade de Letras, 23-25 out. 1995. Rio de Janeiro, Timing Editora, UFRJ, Curso de Pós-graduação em Letras Vernáculas, CNPq: 43-83.

(1996c) Variação Lingüística, Mídia e Preconceito Lingüístico. Revista Internacional de Língua Portuguesa (RILP), 16. Lisboa: Associação das Universidades de Língua Portuguesa: 17:27.

(1997) Concordância nominal e funcionalismo. Alfa, 41 (n-esp). São Paulo: UNESP: 181-206.

(1998) Variação da concordância nominal no português do Brasil: 
influência das variáveis posição, classe gramatical e marcas precedentes. In: S. GroBe \& K. ZimmermanN (eds.) Substandard e mudança lingüística no português do Brasil. Frankfurt am Main, TFM: 153-89.

(no prelo) Paralelismo lingüístico. Estudos da Linguagem, 7(2). Belo Horizonte, Faculdade de Letras da UFMG.

Scherre, M. M. P. et alii (1998) Phonic parallelism: evidence from the imperative in Brazilian Portuguese. In: Paradis, C. et alii (eds.) Papers in Sociolinguistics. NWAVE-26 à l'Université Laval (Québec): Nota Bene: 63-72.

Scherre, M. M. P. \& A. T. de Macedo (1989) Variação e Mudança: o Caso do S pós-vocálico. ABRALIN - Boletim da Associação Brasileira de Lingüística, 11. São Paulo: Unicamp: 165-80.

(1996) Phonetic and lexical effects: post-vocalic $-\mathrm{S}$ in Rio de Janeiro Portuguese. Comunicação apresentada no 25 New Ways of Analyzing Variation (NWAVE). Las Vegas :University of Nevada.

Scherre, M. M. P. \& A. J. Naro (1991) Marking in Discourse: Birds of a Feather. Language Variation and Change, 3. Cambridge University Press: 23-32.

(1992) The serial effect on internal and external variables. Language Variation and Change, 4 (1). Cambridge University Press: 1-13.

(1993) Duas dimensões do paralelismo formal na concordância de número no português popular do Brasil. D.E.L.T.A., 9 (1): 1-14.

(1997) A concordância de número no português do Brasil: um caso típico de variação inerente. In: D. da Hora (org.) Diversidade lingüística no Brasil. João Pessoa: Idéia: 93-114.

(1998a) Restrições sintáticas e semânticas no controle da concordância verbal em português. Fórum lingüístico, 1. Universidade Federal de Santa Catarina, Centro de Comunicação e Expressão, Pós-graduação em Lingüística. Florianópolis: Imprensa Universitária: 45-71.

(1998b) Hierarquização do controle da concordância no português moderno e medieval: o caso de estruturas de sujeito simples. Comunicação apresentada no Colóquio Internacional- projetos de investigação lingüística sobre o português do Brasil. Berlim.

SiLva, G. M. de O. (1991) Um caso de definitude. Organon, 18 (5) - A variação no português do Brasil. Porto Alegre: UFRGS-Instituto de Letras: 90108.

(1994) Uma nova variável sociolingüística - Velhas e novas (histórico). Boletim da ABRALIN, 15. Salvador, UFBA: 243-49.

(1996a) Variáveis sociais e perfis do Corpus Censo. In: G. M. de O e Silva \& M. M. P. Scherre (orgs.) Padrões sociolingüísticos - análises 
de fenômenos variáveis do português falado no Rio de Janeiro. Rio de Janeiro: Tempo Brasileiro: 51-81.

(1996b) Estertores do possessivo seu na terceira pessoa. In: G. M. de O. e Silva \& M. M. P. Scherre (orgs.) Padrões Sociolingüísticos - Análises de fenômenos variáveis do português falado no Rio de Janeiro. Rio de Janeiro: Tempo Brasileiro: 168-81.

(1996c) Realização facultativa do artigo definido diante de possessivos e patronímicos. In: G. M. de O. e Silva \& M. M. P. Scherre (orgs.) Padrões Sociolingüísticos - Análises de fenômenos variáveis do português falado no Rio de Janeiro. Rio de Janeiro: Tempo Brasileiro: $119-45$.

Silva, G. M. de O. et alii (1996) Marcadores discursivos: traços definidores. In: I. G. V. Косн. Gramática do português falado, VI: Desenvolvimentos. São Paulo: UNICAMP/FAPESP: 21-94.

Silva, G. M. de O. e \& A. T. de Macedo (1992) Discourse markers in the spoken Portuguese of Rio de Janeiro. Language Variation and Change, 4(2). Cambridge: Cambridge University Press: 235-49.

(1996) Análise sociolinguística de alguns marcadores conversasionais. In: A. T. Macedo, C. Roncarati \& M. C. Mollica. Variação e discurso. Rio de Janeiro: Tempo Brasileiro: 63-74.

Silva, G. M. de O. e \& M. da C. A de Paiva (1996) Visão de conjunto das variáveis sociais. In: G. M. de O e SiLva \& M. M. P. ScherRe (orgs.) Padrões sociolingüísticos - análises de fenômenos variáveis do português falado no Rio de Janeiro. Rio de Janeiro: Tempo Brasileiro: 336-78.

Silva, G. M. de O. e \& M. M. P. Scherre (1996) (orgs.) Padrões sociolingüísticos - análises de fenômenos variáveis do português falado no Rio de Janeiro. Rio de Janeiro, Tempo Brasileiro.

Silva, G. M. de O. e \& S. J. Votre (1991) Estudos sociolingüísticos no Rio de Janeiro. D.E.L.T.A., 7(1): 357-76.

Silva Neto, S. da (1986) História da língua portuguesa. Rio de Janeiro: Presença.

TARAllo, F. (1983) Relativization strategies in Brazilian Portuguese. Philadelphia: Universidade da Pensilvania, Tese de Doutorado. (1989) (org.) Fotografias Sociolingüísticas. São Paulo: Pontes. (1991) Debate a Oliveira e Silva e Votre. D.E.L.T.A., 7(1): 377-93. (1993) Sobre a alegada origem crioula do português brasileiro: mudanças sintáticas aleatórias. In: I. RoberTs \& M. A. Kato (orgs.) Português brasileiro - uma viagem diacrônica. Campinas, SP: Editora da UNICAMP: 35-68. 
Thibault, P. \& D. Vincent (1990) Un corpus de français parlé - Montréal 84: historique, méthodes et perspective de recherche. Québec: Université Laval.

Veado, R. M. A. (1982) Comportamento lingüístico do dialeto rural. Belo Horizonte: UFMG/PROED.

Votre, S. J. \& A. J. NAro (1989) Mecanismos funcionais do uso da língua. D.E.L.T.A., 5(2): 169-84.

Vogt, C. \& P. Fry. (1997) A “descoberta" do Cafundó. Quilombos em São Paulo - tradição, direitos e lutas. São Paulo: IMESP: 82-102.

WeinReich, U., W. Labov \& M. I. Herzog (1968) Empirical foundations for a theory of language change. In: W. Lehmann \& Y. Malkiel. Directions for historical linguistics: a symposium. Austin: University of Texas Press: 95-188. 